\title{
PENGEMBANGAN WISATA KOTA PADANG SEBAGAI DESTINASI WISATA KOTA DI SUMATERA BARAT
}

\author{
Rozana Eka Putri \\ Program Studi Pendidikan Geografi STKIP PGRI Sumatera Barat \\ rozanawirman@gmail.com
}

\begin{abstract}
Abstrak
Padang is the capital city of West Sumatra lies on the western shore of the island of Sumatra is an area of great tourist destination to visit due to have a natural potential that is different from other areas and also has the potential to represent the culture of Minangkabau culture such as museums Aditiawarman, bridges and other sitinurbaya. Tourism Development of the City field will be an interesting trend in the future by many rational reasons, it can increase revenue. Regional or PAD Asi income can be increased through tax Hotel, Restaurant Tax and Economic Activity Increases in urban areas. Some of the obstacles that could hinder the development of tourism in the city of the plain, namely: 1) the ineffectiveness of the regulation in order to control the effectiveness of development and tourism development. With regard to the regional autonomy in the implementation of development demanded the regulation of executive functioning optimally on the development of culture and tourism 2) Lack of tourism facilities and infrastructure. Their facilities and infrastructure in the region repfesentatif travel site is a certain appeal. 3) The lack of coordination and cohesion among stakeholders as well as program-related sectors. The role and involvement of stakeholders in the development of culture and tourism is still lacking, particularly in the development of an area. 4) Lack of quality and quantity of tourism human resources professional and highly capable. Tourism players are very less in number and quality is not in accordance with the existing resources in the office or in the field. 5) Not optimal marketing and promotional programs that provide positive contribution to revenue (PAD) Implementation of tourism promotion uncultivated areas is not optimal, elements of tourism promotion is expected to be the main tool to destination to the city of Padang. 6) There optimal development of management and conservation of objects and tourist Drag and local cultures. The need for the development and preservation of regional destinations, such as for regional cultural tourism and history as a leading tourism destination and objects. 7) Not optimal network is a community-basedpartnerships. Required professional handling of stakeholders involvement of stakeholders in tourism development efforts are directed
\end{abstract}

\section{PENDAHULUAN}

Secara Geografi kota Padang terletak di pesisir pantai barat pulau Sumatera, dengan garis pantai sepanjang $84 \mathrm{~km}$. Luas keseluruhan Kota Padang adalah 694,96 $\mathrm{km}^{2}$, dan lebih dari $60 \%$ dari luas tersebut, sekitar $\pm 434,63 \mathrm{~km}^{2}$ merupakan daerah perbukitan yang ditutupi hutan lindung, sementara selebihnya merupakan daerah efektif perkotaan. Sedangkan keadaan topografi kota ini bervariasi, 49,48\% luas wilayah daratan Kota Padang berada pada wilayah kemiringan lebih dari 40\% dan 23,57\% berada pada wilayah kemiringan landai. Padang sebagai ibukota Propinsi Sumatra Barat mempunyai luas wilayah administratif sekitar $1.414,96 \mathrm{~km}^{2}$ terletak dipesisir pantai Barat Pulau Sumatra. pada posisi astronomis antara $00^{\circ} 05^{\prime} 05^{\prime \prime}$ BT

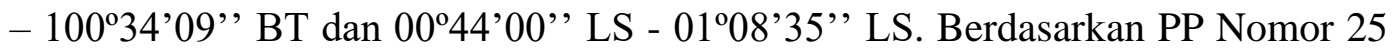
Tahun 1980 dan Perda Nomor 10 Tahun 2005 wilayah administrasi Kota Padang 
terdiri dari 11 Kecamatan dengan 104 Kelurahan. Luas wilayah terdiri dari 694,96 $\mathrm{km}^{2}$ daratan dan 720,00 $\mathrm{km}^{2}$ peariran/laut yang merupakan hasil perluasan Kota Padang Tahun 1980, yaitu penambahan luas wilayah dengan 3 kecamatan dan 15 kelurahan.

Perluasan wilayah administrasi Kota Padang terjadi dengan menggabungkan 3 kecamatan dalam wilayah Kabupaten Padang Pariaman, yaitu sebelumnya memiliki kedekatan sosial budaya dengan Kota Padang atau yang lebih dikenal dengan sebutan Padang Luar Kota, yaitu Kecamatan Nanggalo, Koto Tangah, Kecamatan Pauh dan Kecamatan Bungus Teluk Kabung. Oleh karena itu luas wilayah dan alasan efektivitas pembangunan, ketiga kecamatan tersebut dijadikan 7 kecamatan. Pembentukan wilayah kecamatan baru mempertimbangkan struktur sosial budaya masyarakat dan kesatuan adat nagari agar tidak terpisahkan, maka wilayah administrasi kecamatan disesuikan dengan kesatuan adat nagari yang sudah ada. Sedangkan tambahan 1 (satu) kecamatan lagi adalah Kecamatan Padang Utara yaitu berasal dari sebagian wilayah Nagari Koto Tangah dan sebagian wilayah Kecamatan Padang Barat lama. Batas - batas wilayah Kota Padang, adalah: Sebelah Utara berbatasan dengan Kabupaten Padang Pariaman, Sebelah Timur berbatasan dengan Kabupaten Solok, Sebelah Selatan berbatasan dengan Kabupaten Pesisir Selatan, Sebelah Barat berbatasan dengan Samudera Hindia.

Daerah efektif kota Padang termasuk sungai adalah 205,007 $\mathrm{km}^{2}$ dan daerah bukit termasuk sungai adalah 486,209 $\mathrm{km}^{2}$.Kota Padang terdiri dari 11 kecamatan yaitu Bungus Teluk Kabung, Lubuk Kilangan, Lubuk Begalung, Padang Selatan, Padang Timur, Padang Barat, Padang Utara, Nanggalo, Kuranji, Pauh dan Koto Tangah dengan luas wilayah keseluruhan sejumlah 694,96 $\mathrm{km}^{2}$. Dengan kondisi morfologi tersebut menjadikan kota padang memilki potensi alam dan potensi budaya yang bisa dikembangkan sebagai destinasi wisata disumatera barat. Potensi alam yang dimiliki seperti kondisi pantai yang indah, masyarakat yang ramah, kuliner dan potensi budaya yang dimiliki seperti museum Aditiawarman, jembatan Siti Nurbaya, dan lainnya. Namun Keberadaan pariwisata ini dapat menimbulkan dampak positi dan negative dalam kehidupan masyarakat kota padang dalam hal ekonomi, sosial-budaya, dan lingkungan. Dari segi positifnya pariwisata berfungsi sebagai jalan keluar bagi persoalan kemiskinan, konservasi, pemberdayaan, dan lainnya. Namun hal ini perlu diperhatikan oleh semua pihak seperti pemerintah, 
stakeholder, masyarakat dan pemerhati lingkungan. Sehingga potensi yang ada ini dapat dikembangkan dan dampak negative yang timbul akibat kegitan pariwisata ini dapat diminimalisir. Oleh karena itu perlu adanya sebuah pengelolaan pariwisata yang baik yang berwawasan lingkungan Melalui pengelolaan wisata kota Padang sehingga bisa menjadi sector andalan dimasa datang.

\section{PEMBAHASAN}

I. Alasan Perlu adanya Pengelolaan wisata kota di kota Padang

Kota merupakan suatu daerah yang didalamnya terdapat fungsi-fungsi yang dapat memberikan pelayanan dan kepuasan kepada masyarakat. Sebuah kota dapat dilihat perkembangannya dari adanya sejumlah sarana dan prasarana yang lengkap dan didukung oleh teknologi yang canggih dan mudah diakses oleh masyarakat. Dan sebuah kota yang berkembang dengan baik juga dapat dilihat dari majunya sector pariwisata ditempat tersebut baik itu pariwisata alami maupun pariwisata buatan.

Pengembangan pariwisata kota di Kota Padang perlu dilakukan karena Padang memiliki :

a. Balai Kota Padang : kota Padang memiliki Balai Kota yang sengaja dibangun untuk di gunakan sebagai jantung pemerintahan kota. Bangunan ini dibangun dengan arsitektur yang sangat indahnya dan memiliki karakteristik tertentu sesuai ciri khas sebuah kota yang kental dengna adat dan budaya Minangkabau.

b. Kawasan Jalan tertentu yang biasanya memiliki mitologi tertentu seperti horor, nostalgia, historis, heroik, dan sebagainya yang biasanya melekat dan menjadi ciri khas tersendiri bagi setiap kota. Kawasan jalan yang dimiliki kota padang yang menjadi ikon kota adalah jalan Samudra, Jalan Sitinurbaya dan lain-lain

c. Monumen Kota, yang memiliki pesan edukasi historis atau sosial atau religius yang dimiliki yaitu monument Gempa tanggal 30 September 2009 dan monument perdaimaian.

d. Kuliner juga menjadi daya tarik tersendiri yang dapat dikemas oleh setiap masyarakt dikota padang yang dapat dijadikan untuk daya tarik wisata yang menarik. Seperi Rendang, karupuk Balado, kerupuk Sanjai, Dakak-dakak, Goreng Baluik dan lamang tapai 
e. Kampus atau Universitas yang memang dirancang dan citrakan sebagai aset kota yang dapat dijadikan daya tarik wisata edukasi, dan ciri ini juga dimiliki kota Kota Padang Yaitu Universitas Andalas, Universitas Negeri Padang, STKIP PGRI Sumatera Barat, dan lainya masih banyak lagi.

f. Mall atau Pusat perbelanjaan atau Pasar Tradisional juga menjadi ciri khas bagi kota Padang dan akan menjadi daya tarik yang amat penting untuk dikemas menjadi daya tarik wisata kota.

g. Alun-alun dan Taman Kota adalah ruang terbuka yang biasanya menjadi daya tarik wisata kota dan juga melekat pada identitas sebuah kota.

h. Museum Kota juga dimiliki kota padang yaitu Musium Adiatiawarman yang biasanya dikelola sebagai bagian dari wujud pelestarian terhadap benda-benda purbakala warisan sebuah kota yang mungkin bernilai mitos, atau warisan budaya. Dan banyak lagi potensi daya tarik wisata kota yang dapat dikembangkan seperti misalnya taman rekreasi dan sebagainya mengikuti kreatifitas masyarakat.

Pengembangan Wisata Kota padang akan menjadi trend menarik dimasa depan berdasarkan banyak alasan yang rasional,hal ini dapat Meningkatkan pendapatan Asli daerah. Pendapatan Asi Daerah atau PAD dapat ditingkatkan melalui Pajak Hotel, pajak Restauran dan Meningkatkan Aktivitas Ekonomi di perkotaan. Hal ini senada dengan pendapat Cox (1985) dalam Pitana (2009) tentang alasan pentingnya pengelolaan pariwisata kota yang harus mengedepankan memperhatikan prinsip-prinsip sebagai berikut:

1. Pembangunan dan pengembangan pariwisata haruslah didasarkan pada kearifan local dan special local sense yang merefleksikan keunikan peninggalan budaya dan keunikan lingkungan.

2. Preservasi, proteksi, dan peningkatan kualitas sumber daya yang menjadi basis pengembangan kawasan pariwisata.

3. Pengembangan atraksi wisata tambahan yang mengakar pada khasanah budaya lokal.

4. Pelayanan kepada wisatawan yang berbasis kepada keunikan budaya dan lingkungan lokal. 
5 Memberikan dukungan dan legitimasi pada pembangunan dan pengembangan pariwisata jika terbukti memberikan manfaat positif, tetapi sebaliknya mengendalikan dan/atau menghentikan aktivitas pariwisata tersebut jika melampui ambang batas lingkungan alam atau akseptabilitas sosial walaupun di sisi lain mampu meningkatkan pendapatan masyarakat

II. Kendala, Hambatan dan Tantangan dalam Pengelolaan Pariwisata kota di kota padang

Berdasarkan hasil observasi terhadap pengelolaan kawasan pariwisata dikota padang, terdapat beberapa kendala yang dapat menghambat perkembangan pariwisata kota dikota padang, yaitu:

1) Belum efektifnya regulasi dalam rangka efektifitas pengembangan dan pengendalianpembangunan pariwisata. Berkenaan dengan itu otonomisasi daerah dalam pelaksanaanpembangunan dituntut adanya peraturan terhadap fungsi pelaksanaan secara optimal padapengembangan kebudayaan dan pariwisata

2) Kurangnya sarana dan prasarana pariwisata. Adanya sarana dan prasarana yang repfesentatif pada kawasan site wisata merupakan daya tarik tertentu untuk dikunjungiwisatawan.Namun, kondisi sarana dan prasarana belum memadai.

3) Tidak adanya koordinasi dan keterpaduan program antar stakeholder maupun sector terkait. Peran serta keterlibatan stakeholders dalam pengembangan kebudayaan danpariwisata masih sangat kurang, terutama dalam pengembangan suatu kawasan.

4) Kurangnya kualitas dan kuantitas sumber daya manusia pariwisata yang professional danberkemampuan tinggi. Pelaku pariwisata sangat kurang jumlahnya dan kualitasnya tidak sesuai dengan sumber daya yang ada di dinas maupun dilapangan.

5) Belum optimalnya program promosi dan pemasaran yang memberikan konstribusi positifterhadap Pendapatan Asli Daerah (PAD) Pelaksanaan promosi wisata daerah belum optimaldigarap, unsur promosi pariwisata diharapkan menjadi alat utama untuk melakukan destinasike kota Padang

6) Belum optimalnya pengembangan pengelolaan dan pelestarian obyek dan daya Tarik wisata dan kebudayaan daerah. Perlunya pengembangan dan 
pelestarian kawasan destinasi seperti untuk kawasan obyek wisata budaya dan sejarah sebagai daerah destinasi dan obyekpariwisata unggulan.

7) Belum optimalnya jaringan hubungan kemitraan yang berbasis kerakyatan. Diperlukanpenanganan yang professional dari stakeholders keterlibatan stakeholders dalam usahapengembangan pariwisata yang diarahkan kepada adanya kebersamaan (mutuality) pola pikir

\section{KESIMPULAN}

Berdasarkan pembahasan diatas maka penulis dapat menyimpulkan antara lain sebagai berikut :

1. Pengembangan Wisata Kota padang akan menjadi trend menarik dimasa depan berdasarkan banyak alasan yang rasional ,hal ini dapat Meningkatkan pendapatan Asli daerah. Pendapatan Asi Daerah atau PAD dapat ditingkatkan melalui Pajak Hotel, pajak Restauran dan Meningkatkan Aktivitas Ekonomi di perkotaan..

2. Beberapa kendala yang dapat menghambat perkembangan pariwisata kota dikota padang, yaitu: 1) Belum efektifnya regulasi dalam rangka efektifitas pengembangan dan pengendalian pembangunan pariwisata. Berkenaan dengan itu otonomisasi daerah dalam pelaksanaan pembangunan dituntut adanya peraturan terhadap fungsi pelaksanaan secara optimal pada pengembangan kebudayaan dan pariwisata 2) Kurangnya sarana dan prasarana pariwisata. Adanya sarana dan prasarana yang repfesentatif pada kawasan site wisata merupakan daya tarik tertentu. 3) Tidak adanya koordinasi dan keterpaduan program antar stakeholder maupun sector terkait. Peran serta keterlibatan stakeholders dalam pengembangan kebudayaan dan pariwisata masih sangat kurang, terutama dalam pengembangan suatu kawasan.4) Kurangnya kualitas dan kuantitas sumber daya manusia pariwisata yang professional dan berkemampuan tinggi. Pelaku pariwisata sangat kurang jumlahnya dan kualitasnya tidak sesuai dengan sumber daya yang ada di dinas maupun dilapangan.5) Belum optimalnya program promosi dan pemasaran yang memberikan konstribusi positif terhadap Pendapatan Asli Daerah (PAD) Pelaksanaan promosi wisata daerah belum optimal digarap, unsur promosi pariwisata diharapkan menjadi alat utama untuk melakukan destinasi ke kota Padang. 6) Belum optimalnya pengembangan pengelolaan dan pelestarian obyek 
dan daya Tarik wisata dan kebudayaan daerah. Perlunya pengembangan dan pelestarian kawasan destinasi, seperti untuk kawasan obyek wisata budaya dan sejarah sebagai daerah destinasi dan obyek pariwisata unggulan.7) Belum optimalnya jaringan hubungan kemitraan yang berbasis kerakyatan. Diperlukan penanganan yang professional dari stakeholders keterlibatan stakeholders dalam usaha pengembangan pariwisata yang diarahkan

\section{DAFTAR PUSTAKA}

Nurdiyansah. DMO Sebagai pengelolaan pariwisata. Journal

I Gusti Bagus Rai Utama.Pengembangan Wisata kota sebagai pariwisata masa depan indonesia.

http://www.academia.edu/4226025/pengembangan_wisata_kota_sebagai_pariwisa ta_masa_depan_indonesia_.universitas dhyana pura, badung-bali. http://ardhikurniawan.blogspot.co.id/p/blog-page_23.html 